\title{
Spreadsheet Design: An Optimal Checklist For Accountants
}

Jeffrey N. Barnes, CPA, MAcc, Southern Utah University, USA

David Tufte, PhD, Southern Utah University, USA

David Christensen, PhD, CMA, Southern Utah University, USA

\begin{abstract}
Just as good grammar, punctuation, style, and content organization are important to well-written documents, basic fundamentals of spreadsheet design are essential to clear communication. In fact, the very principles of good writing should be integrated into spreadsheet workpaper design and organization. The unique contributions of this paper are an integration of a review of the literature on spreadsheet design, with the results of a convenience survey of CPAs, and a "Spreadsheet Design Checklist" for pedagogy. The checklist is intended as a reference for use until the student or professional becomes proficient in basic spreadsheet design and organization and the checklist becomes just as "second nature" as creating well-written memoranda.
\end{abstract}

Key phrases: spreadsheet design, spreadsheet organization, spreadsheet checklist, history of spreadsheet design.

\section{INTRODUCTION}

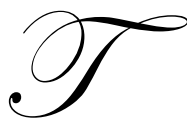

here are many articles published in major business-related journals concerning specific functional uses of spreadsheets. The Journal of Accountancy, for example, regularly features an article on the efficient and effective use of spreadsheets (AICPA). Such articles usually focus on completing a specific task to create a desired output. A scan of EBSCO business journal databases brings up thousands of articles in response to the word "spreadsheets."

However, the number of articles dwindles substantially when a modifier such as "organization," or "design," is used. Most such articles are outdated and incomplete with respect to providing basic guidelines for professional spreadsheet workpaper design, organization, and presentation. Just as good grammar, punctuation, style, and content organization are important to well-written prose, there are fundamentals of spreadsheet design which are essential to clear communication. In fact, the very principles of good writing should be integrated into spreadsheet workpaper design and organization. Further, Bhavnani, Peck and Reif (2008) provide evidence that proactive instructional strategies can help users acquire more effective and efficient computer skills.

The unique contributions of this paper are to review the literature on spreadsheet design and organization, survey results from a convenience sample of CPAs, with manager- or partner-level experience, and to present a "Spreadsheet Design Checklist." The checklist is intended as a reference for use until the student or professional becomes proficient in basic spreadsheet design and organization and the checklist becomes just as "second nature" as creating well-written memoranda.

\section{HISTORICAL DEVELOPMENT OF SPREADSHEET SOFTWARE}

It has been just over 30 years since the first spreadsheet program was loaded onto a personal computer platform. Table 1 below provides the historical development of the major spreadsheet programs (Pemberton, 2000, p. 380): 
Table 1

Spreadsheet Software Development

\begin{tabular}{ccc}
\hline Software & Year of Introduction & Operating Platform \\
\hline VisiCalc & 1979 & Apple II \\
SuperCalc & 1980 & CP/M \\
Multiplan & 1982 & DOS \\
Lotus 1-2-3 & 1983 & DOS \\
Quattro Pro & 1987 & DOS \\
Excel & 1987 & DOS/Windows \\
\hline
\end{tabular}

Source: Pemberton, 2000.

VisiCalc, introduced in 1979, was the software product that really propelled the use of personal computers by professionals (Coffee, 2004). Dan Bricklan, co-inventor of VisiCalc, believed that the spreadsheet was something that society needed and that it would have been invented if he had not invented it (Bender, 2004). Today, Microsoft Excel is the most widely used business spreadsheet program, claiming well over 90 percent of the market (Pemberton, 2000, p. 380). Alexander (2006) stated that there are "about 400 million customers worldwide using Microsoft Office, which includes the spreadsheet application as one of its components" (p. 22). This high market share clearly suggests to educational professionals that in the great majority of cases they should use Excel for instruction and assignments. In this article, any specific reference to spreadsheet terminology applies to the Microsoft environment.

\section{COLLEGE STUDENTS' SPREADSHEET DESIGN COMPETENCIES}

Because spreadsheets have been around for at least 30 years, one would assume that entering college and university students would have adequate data organization skills and ability to construct properly designed spreadsheets. Unfortunately, recent research has shown that only about 25 percent of college-entering freshmen have sufficient organizing data skills and competencies (Gaide, 2004, p. 5). This low percentage suggests that the precollege training to the spreadsheet education process is initially weak. ${ }^{1}$

The output of spreadsheet education is also weak. Studies of experienced spreadsheet professionals ${ }^{2}$ in controlled experimental environments showed that errors were common (Brown \& Gould, 1987). Even worse, Panko and Sprague (1997 and 1999) showed that while exposure to more disciplines allowed users to model situations with spreadsheets more readily, that same exposure did not lead to fewer errors in those spreadsheets.

Two strategies have been tested to improve spreadsheet quality: (1) training in spreadsheet design, and (2) working in teams. Training in spreadsheet design has been tested by Janvrin and Morrison (2000a and 2000b), as well as by Kreie, Cronan, Pendley and Renwick (2000). The result was a statistically insignificant reduction in errors. Alternatively, working in teams was shown by and Halverson (1997 and 1998) to significantly reduce errors. However, managers are unlikely to find this to be a reasonable solution for general use.

The lack of adequate spreadsheet design and organization skills is probably a function of several factors. For example, Reimann and Neubert (2000, p. 316) discovered when people learn a new software program, they often "jump the gun." Right after installation, they start the software and try to use it without reading the manual first. In the process, they develop bad habits, which become difficult to change. In the specific case of spreadsheets, Hassinen (1988) showed that paper and pencil design helped avoid errors and the advanced spreadsheet engineering text by Powell and Baker (2004) devotes the first three of nine chapters to encouraging this practice. The overall impression is clearly stated in the summary of Chadwick, Knight, and Clipsham (1997) stated, "users are trained how to do things right but not how to avoid doing things wrong” (as cited by Panko, R., 2009)

In the authors' own experience, unless students receive specific instructions concerning spreadsheet presentation, they will ignore some of the most basic principles of professional written communication when preparing spreadsheets. In one experiment (Porter, 2005), junior and senior students in an operations management class were assigned a relatively simple problem that involved using a spreadsheet to calculate and present tables of break-even points. Of the 60 spreadsheets submitted, the majority contained stylistic or formatting errors that would 
have been obvious to most students had they been submitting a professional memo, rather than a spreadsheet. For example, thirty of the spreadsheets had inappropriately formatted column titles, lacking centering, boldface, underlining, and/or initial caps. Thirty percent of the students had used floating, rather than fixed, decimals in the columns, resulting in non-aligned decimal points as the reader moved down the column.

The point here is that the average student does not see the need to apply to spreadsheets the conventions and rules developed over the years for professional letters and memos, even though such conventions and rules clarify the communication process. While true that not all such rules will apply, spreadsheets can borrow much from the conventions of other professional written communications. With the passage of time spreadsheet users likely will, or at least should, develop additional rules and conventions to enhance and clarify communication. The authors hope that this paper will contribute to the rules for good spreadsheet design, organization, and presentation.

\section{WRITTEN COMMUNICATION OBJECTIVES TRANSFER TO SPREADSHEET DESIGN}

The need for well-designed, well-organized, and professionally presented spreadsheet workpapers is as critical to a young professional's career aspirations as having other excellent communication skills. A study by Christensen and Rees (2002) highlighted the necessity, and importance to the employer, of excellent communication skills. The authors identified and ranked by importance 32 business communication skills cited in business literature. They then measured the level of employer satisfaction with college preparation in those skills. Specifically, four of the identified skills relate to the requirements for effective spreadsheet workpapers: edits and revises documents conscientiously, organizes information effectively, writes persuasively, and writes clearly. These four requirements, as ranked by the Christensen and Rees' research, are deemed by employers to be the most important yet lacking in newly hired employees.

Table 2

Writing Skills Transferable to Spreadsheet Design

\begin{tabular}{lcc}
\hline \multicolumn{1}{c}{ Writing Skills } & Importance Mean & Satisfaction Mean \\
\hline Edits and revises documents conscientiously & 3.94 & 2.91 \\
Organizes information effectively & 4.20 & 2.86 \\
Writes persuasively & 3.40 & 2.90 \\
Writes well—clearly, concisely, correctly, completely & 4.42 & 2.68 \\
\hline
\end{tabular}

Source: Christensen and Rees, 2002.

Importance was rated on a five-point scale, where:

1 - unimportant, 2 - somewhat unimportant, 3 = important, 4 = very important, $5=$ extremely important

Satisfaction was rated on a five-point scale, where:

1 - very dissatisfied, 2 - somewhat dissatisfied, $3=$ neither satisfied nor dissatisfied, $4=$ very satisfied, $5=$ extremely dissatisfied

As evidenced in Table 2, employers are dissatisfied with accounting students' ability to effectively edit, revise, and organize information in written documents (Christensen \& Rees, 2002, p. 5). Cragg and King (1993) and Panko (2008) discussed the poor or nonexistent spreadsheet editing and revision protocols within firms. Because much of the writing accounting employers would be commenting on would be employee-produced accounting workpapers, it makes sense that poor writing skills extend to poor spreadsheet formatting and design.

Anecdotally, a professor at a southwestern university is constantly reminding students to properly edit, revise, and organize their information more effectively on spreadsheet assignments. He said, "I am constantly requiring students to properly label their columns, properly format their decimals for consistency, and correct grammatical errors, and providing ideas on how to more effectively display their work on spreadsheets" (Porter, 2005). A well-cited accounting research study has shown that increased communication skills are necessary, especially for accounting majors (Albrecht and Sack, 2000). 
In a recent research project, CFO-IT asked 168 finance executives about the state of IT as used by corporate finance departments. This research, administered in the summer of 2004, covered small and large companies, and revealed the following information about businesspersons' perception regarding spreadsheetbeneficial business information attributes, see Table 3 below (Durfee, 2004, p. 34).

Table 3

Desirability of Spreadsheet Features

\begin{tabular}{lcc}
\hline \multicolumn{1}{c}{ Beneficial Attributes } & Excellent & Good \\
\hline Accuracy & 51 & 37 \\
Ease of Use & 50 & 44 \\
Capabilities/Power & 46 & 49 \\
Labor-Saving Potential & 29 & 47 \\
Integration with Other Systems & 10 & 46 \\
\hline
\end{tabular}

Note: all entries are in percentages.

The survey also indicated that more than twice as many firms expect the importance of spreadsheets to increase rather than decrease. Regardless of future expectations, professionals need to improve their spreadsheet design and organizational competencies. To meet the needs of business professionals, colleges and universities will need to provide better-prepared spreadsheet-skilled professionals.

\section{LITERATURE REVIEW}

\section{The Earlier, the Better}

Technology literacy has become as fundamental to a person's ability to navigate through society as the traditional three "R's." Graham and her team initiated a "Core Competency Assessment" as part of Carroll Community College's continued efforts in the area of learning outcomes assessments. What Graham quickly discovered was that along with the traditional core competencies of reading, writing, and math, a new core competency, computer technology skills, needed to be addressed. Graham's research found that only 25 percent of the entering students had sufficient organizing data skills and competencies required for spreadsheet platforms (as cited in Gaide, 2004, pp. 5-7). For most young business professionals, developing the skills for effective spreadsheet communication should begin early in their collegiate experience.

\section{Spreadsheet Design Objectives}

Ragsdale (2004) stated, "Creating spreadsheets that effectively communicate their purpose is very much an art—or at least an acquired skill" (p. 62). Consequently, there are no hard and fast rules regarding the way problems should be modeled; however, some modeling methods are more logical than others. The following objectives for good spreadsheet design have been identified:

- Communication. A spreadsheet's primary business purpose is that of communicating information to managers. As such, the primary design objective in most spreadsheet-modeling tasks is to communicate the relevant aspects of the problem at hand in as clear and intuitively appealing manner as possible.

- $\quad$ Reliability. The output a spreadsheet generates should be correct and consistent. These two qualities have an obvious impact on the degree of confidence a manager places in the results of the modeling effort.

- $\quad$ Auditability. A manager should be able to retrace the steps followed to generate the different outputs from the model in order to understand the model and verify results. Models that are set up in an intuitively appealing, logical layout tend to be the most auditable.

- $\quad$ Modifiability. The data and assumptions upon which we build spreadsheet models can change frequently. A well-designed spreadsheet should be easy to change or enhance in order to meet dynamic user requirements. (Ragsdale, 2004, p. 62) 


\section{Earliest Guidelines}

Along with the above spreadsheet design objectives, spreadsheet designers, as with good document designers, should take into consideration the objectives of good form design. The spreadsheet designer should

- $\quad$ outline some general spreadsheet considerations (purpose of the spreadsheet, logical modular components, etc.),

- identify introductory section items to be included in the spreadsheet (adequately descriptive heading, proper use of header and footer functions, necessity of an assumption and input section, etc.),

- fashion the main body of the spreadsheet (logically related items grouped together, adequate uses of titles, bolding, shading to improve spreadsheet readability, etc.), and

- determine how overall conclusions are to be communicated (results easily identifiable, results placed in a logical concluding location, etc.). (Romney and Steinbart, 2003, p. 666)

The earliest guidelines for spreadsheet design focused on considerations that would minimize common spreadsheet errors. Broomley (1985) provided the following guidance to eliminate much of the difficulty of template construction:

- $\quad$ Template planning. A well-thought-out plan should be completed before the template is constructed, taking into account the spreadsheet's purpose, the input required and the solution generated. Hassinen 1988 shows that planning on paper is helpful, and Powell and Baker 2004 advocate this in their text.

- Modular construction. Another useful technique is to keep the spreadsheet as simple as possible. Small sections of the model should be created and tested, and once they are working properly they can be combined with other portions of the template.

- Decomposition of formulas. The decomposition of long formulas and complex macros is another method of model simplification, e.g. two smaller formulas in two different cells, rather than a complicated formula in a single cell. Overly complicated commands lead to interpretation errors and are difficult to revise.

- Labeling cell ranges. The last overall technique is to define names for cell ranges. This reduces the probability of cell reference errors caused by moving a column or row to another position. (Broomley, p. 134)

\section{Spreadsheet Design Recommendations}

Some of the earliest spreadsheet articles emphasized the necessity of migrating from paper workpapers to the use of spreadsheets. These early articles discussed the necessity of proper spreadsheet planning, just as was necessary for hand-written workpapers. One article indicated that planning consisted first of specifying the information needed to develop the spreadsheet and possible multiple uses of such information, and second, considering the changes that might be needed in the future. The second feature, consideration of changes, can be accomplished by breaking the spreadsheet down to logical components (Bissell \& Needle, 1986, p. 110). Bissell and Needle's article illustrated that a spreadsheet used to analyze the cash flow implications of purchasing an automobile might have the following logical components:

- $\quad$ Heading. The heading should clearly describe the purpose of the spreadsheet.

- Date. Documenting a spreadsheet with a date reference allows a user to know that the printout is the most recent or desired version.

- $\quad$ File name, author, and approval. Placing the file name, author, and names of any approving authorities in the spreadsheet itself can help avoid a frantic search for that information when viewing hard copies in the future.

- Table of contents. A Table of Contents (ToC) quickly identifies the important areas of the spreadsheet. The identification of cell location references will allow you to move efficiently to important areas. The ToC should be in an accessible area, such as the upper-left hand corner of the spreadsheet. 
- $\quad$ Error summary box. An error function that allows a cell value to result in ERR ERROR, \#REF, when an "error condition" (such as deleting a cell in a SUM formula) exists. The error summary box communicates that an ERR exists in a ranged area.

- Assumption/input area. Isolating assumptions and input data allows these factors to be changed without altering the formulas on a spreadsheet.

- $\quad$ Limit-check formulas. Limit checks should be used whenever possible to verify that the assumptions or data entered are valid and that calculated values appear reasonable. Using "if' statements is particularly useful. For instance, $=\mathrm{if}(\mathrm{D} 18>.50$, “CHECK","”) which reads, if cell D18 calculates to greater than 50 percent, write CHECK in the cell, else write nothing.

- Calculations area. This area of the spreadsheet requires no data or modifications when each set of assumptions is entered. Protecting the entire area will help prevent inadvertent changes or modifications.

- $\quad$ Edit-check formulas. A series of edit-check formulas improves the integrity of a spreadsheet and allows the author to be more confident of the results. These edit-check formulas are usually constructed using "if' statements, similar to limit-check formulas above.

- Instruction area. Instructions should detail the important operation points of using a spreadsheet. Comments or instructions, such as the descriptions of the edit checks being performed in the purchase analysis, may also be appropriate in other areas of the spreadsheet (Bissell \& Needle, 1986, p. 114-120).

As spreadsheet functions became more widely used and integrated into a business enterprise, their use became more sophisticated. Increasingly, firms use spreadsheets for ongoing projects that involve many people who need to go in and out of the spreadsheet file, adding material and customizing the output for their specific needs. Repeated-use spreadsheet files differ from one-time-use files. According to Kreie and Pendley (1998), the designer should consider the following steps:

- Design. Decide what you want the spreadsheet to do. List the input data to be used and the output data you want.

- $\quad$ Layout. Lay out the spreadsheet structure and, if necessary, divide it into logically related sections, such as identification, description, model, documentation, and macros.

- $\quad$ Create the spreadsheet. Familiarize yourself with the use of absolute and relative cell references. Their proper use is critical to the success of input, calculation and output areas.

- $\quad$ Test. Test the spreadsheet by selecting a set of test values and then test the results independently of your spreadsheet. (Kreie \& Pendley, 1998, p. 32)

Berglas and Hoare (1999) give good specific advice on constructing business-use spreadsheet models. Survey and anecdotal evidence indicate that spreadsheet errors are common (see Panko's website). Firms can minimize the risk of errors by developing and strictly following good practice modeling protocols, as listed below, and by requiring independent review by someone equipped to do so. Firms should also consider the use of software tools to improve the effectiveness of any review. Specifically, the authors give the following guidelines:

- $\quad$ Never place constants in formulas. They hide assumptions upon which the model is based.

- $\quad$ Break up long-complex formulas into small chunks. This clarifies the meaning of the model and enables the intermediate results to be verified independently.

- $\quad$ Add redundant verification formulas to the model. These can have a form 'if(CellValue $<>$ ExpectedValue, "ERROR","ok")"

- Highlight input values. Shading, bordering, etc. aids in focusing the spreadsheet user to the necessary input.

- $\quad$ Check for inconsistently copied formulas. This can be done by using the Edit/Go To/Special option in Excel.

- Document the spreadsheet carefully. More importantly, ensure that the documentation is maintained as the spreadsheet is changed (Berglas \& Hoare, 1999, p. 42)

Kreie and Pendley (1998) gave some useful recommendations for designing the "perfect" spreadsheet file. They stress that each spreadsheet model should be logically organized and contain the following segregated and 
identified worksheets as components of the total workbook spreadsheet file. The authors strongly encourage labeling the worksheets as follows:

- Identification, including the title, developer, revised date, filename, table of contents with worksheet name or range names.

- $\quad$ Description, explaining the purpose of the worksheet, including a listing of assumptions and calculations to be made.

- $\quad$ Input, containing all the input variables needed to run the worksheet.

- $\quad$ Calculation. These worksheets are usually non-changeable and should be protected.

- $\quad$ Results. These worksheets are usually non-changeable and should be protected.

- $\quad$ Documentation, describing assumptions used to build the model and structure of the calculations made.

- $\quad$ Macros, describing each macro used in the spreadsheet and listing the macro name, type of macro language (e.g. Visual Basic), keyboard shortcut, and purpose ( Kreie \& Pendley, 1998, pp. 32)

Other articles provide insights into better spreadsheet design and organization, including, for example, the importance of collaborating with spreadsheet end-users to better determine the model design and labels (Whittaker, 1999); highlighting input areas from the body of the spreadsheet (Wampler, 2000); using comments within spreadsheets (Lehman, 2001); enhancing spreadsheet accuracy by using easy-to-create graphic messages and input boxes that can provide reminders; explaining various functions of the data tables; helping users find and enter the right data and even refusing to let them proceed unless they follow a prescribed procedure (Mahoney \& Welch, 2003); adding lines and borders only when you are finished making changes to your spreadsheet design, lest you have to reconstruct these lines and borders once again after a change (Keefe, 2000).

Additionally, Powell and Baker (2004) broke spreadsheet engineering into four processes, each broken down into rules. Theirs is a solid synthesis of earlier research, and it adds guidelines for whole workbooks rather than the more basic worksheet recommendations made by others.

\section{Process 1: Designing Worksheets}

Rule 1.1: Sketch it out first - draft the spreadsheet layout on paper.

Rule 1.2: Organize into modules - break the work down into pieces.

Rule 1.3: Start small - make sure each part works before moving on.

Rule 1.4: Isolate input parameters - keep these out of your formulas.

Rule 1.5: Design for use - put inputs and outputs where users can find and use them.

Rule 1.6: Keep it simple - each cell should be understandable to the user.

Rule 1.7: Design for communication - use labels, borders, colors, and blank space to highlight your logic.

Rule 1.8: Document important data and formulas - use comments to make notes.

\section{Process 2: Designing Workbooks}

Rule 2.1: Group similar information onto its own worksheet - in particular, separate your inputs and outputs from your calculations.

Rule 2.2: Make navigation easy - name your worksheets concisely and informatively, and group them in logical order.

Rule 2.3: Protect - protect some or all of your workbook from user initiated changes, and use data validation to ensure that permitted edits are acceptable.

\section{Process 3: Building}

Rule 3.1: Follow your plan - use your draft sketch.

Rule 3.2: Build one module at a time - make incremental investments in the ultimate success of the spreadsheet.

Rule 3.3: Predict the outcome of formulas - know what the answers to your formulas ought to look like before you code them. 
Rule 3.4: Copy and paste formulas carefully - make a point of copying formulas rather than retyping them; there is less room for error.

Rule 3.5: Use relative and absolute addressing - copying and pasting formulas can only work for you if your cell addressing is done appropriately.

Rule 3.6: Use the function wizard - don't bother to memorize function statements when you can easily look them up.

Rule 3.7: Use range names - make your formulas understandable in (relatively) plain language.

Rule 3.8: Use dummy inputs - test your formulas with simple inputs which lead to simple formula results that you can check by hand.

\section{Process 4: Testing}

Rule 4.1: Check for plausibility - test how your model works when you enter extreme inputs.

Rule 4.2: Check your formulas - use the auditing tools and error checking to help your visual check of your formulas.

Rule 4.3: Test for overall plausibility - make sure that plausible changes across a set of inputs lead to plausible changes in outputs. (Powell \& Baker, 2004)

\section{WHAT CPA MANAGERS AND PARTNERS THINK: INDICATIONS FROM A SURVEY}

A convenience pilot sample of $30 \mathrm{CPA}$ managers and partners, from 12 small- to international-sized CPA firms, throughout the U.S., were requested to participate in a survey. Surveys were sent via U.S. postal system in February 2009 and the last responses were received by the end of March 2009. On average, the respondents had over 10 years experience in the public accounting industry. The survey requested respondent's perception of the importance regarding the Spreadsheet Design Checklist's components, constructed by the authors from the secondary research of literature for the past 30 years. A 5-point Likert Scale was used, with labels of Strongly Disagree, Disagree, Neither Disagree or Agree, Agree, and Strongly Agree, ranging from 1 to 5 points, respectively. As Table 4 discloses, 19 respondents, from 11 different firms, provided feedback. There were too few respondent returns to perform any meaningful difference analyses between firm sizes. Additionally, respondents were allowed to write comments after each section of the survey. Authors' generalized meaningful comments in each of the analyses that follow.

Table 4

Demographics of Respondents

\begin{tabular}{lcc}
\hline \multicolumn{1}{c}{ Type of Firm } & Total Number of Respondents Across Firms & Number of Separate Firms with Responses \\
\hline International & 4 & 2 \\
National & 3 & 1 \\
Regional & 5 & 2 \\
Local & 7 & 6 \\
\hline Total & 19 & 11 \\
\hline
\end{tabular}

\section{THE SURVEY INSTRUMENT}

The survey instrument requested a response for each item in the Spreadsheet Design Checklist, provided in the next section. Each question in the Spreadsheet Design Checklist is intended to prompt critical thinking about what could be necessary in designing a business-use spreadsheet. There are five major sections to consider in spreadsheet organization and design, addressed in the survey: General Considerations, General Design Considerations, Introductory Section, Main Body, and Conclusion. As seen in the Spreadsheet Design Checklist, there were

- 4 critical-thinking questions for the overall "General Considerations" section;

- 4 critical-thinking questions for the "General Design Questions" section;

- $\quad 9$ critical thinking questions for the "Introductory" section:

- 7 critical-thinking questions for the "Main Body" section; and,

- 5 critical-thinking questions for the "Conclusion" section 
Each of these five sections' items and the respondents' collective perception of their individual importance are provided in Tables 5 through 9.

\section{ANALYSIS AND DISCUSSION}

The following analysis and discussion simply compares the means, highs, lows, and standard deviations of the public accounting industry respondents' perception of importance of generally accepted spreadsheet design checklist items, as revealed in the literature review of the past 30 years. Additionally, anecdotal comments, written by the responsdents, are generalized to support discussion about the various components of an accountant's professionally designed spreadsheet, used to solve a single problem, or used as a production-use instrument.

Table 5

Descriptive Statistics of Managers' and Partners' Perceptions Regarding The General Considerations Section of the Survey

\begin{tabular}{lcccc}
\hline \multicolumn{1}{c}{ Checklist Item } & Mean & High & Low & St. Dev. \\
\hline Take some time to determine how to properly design your spreadsheet & 4.47 & 5 & 4 & 0.51 \\
Break your spreadsheet down into logical components & 4.37 & 5 & 3 & 0.60 \\
Make use of spreadsheet templates for repeated-use applications & 4.53 & 5 & 3 & 0.61 \\
Always save your spreadsheet with the cursor in a blank cell near the & 3.00 & 4 & 2 & 0.58 \\
top of each worksheet & 4.09 & 4.75 & 3 & 0.57 \\
\hline Average & &
\end{tabular}

\section{Table 5 Analysis}

Table 5 has the second highest collective agreement about the importance of these checklist items. Most accounting managers and partners would expect to see staff-created worksheets possess these general design considerations. Like good writing, spreadsheets should be logically organized. Reviewing the respondents' written comments generally stated that the spreadsheet preparer is advised to think about the audience who will use the spreadsheet, keeping in mind the purpose and expected results to communicate. Additionally, the professional accountant should follow basic standards developed by the organization, and be careful not to be too concern for perfection, that professional work efficiency is decreased.

Table 6

Descriptive Statistics of Managers' and Partners' Perceptions Regarding The General Design Section of the Survey

\begin{tabular}{lcccc}
\hline \multicolumn{1}{c}{ Checklist Item } & Mean & High & Low & St. Dev. \\
\hline Are bold type, double-thick lines, varying colors and shaded areas & 4.21 & 5 & 2 & 0.79 \\
used appropriately? & 3.79 & 5 & 2 & 0.63 \\
Is the font style and size appropriate for the spreadsheet? & 3.68 & 5 & 2 & 0.82 \\
Are varying font sizes consistent as to size and use - text, titles, & 3.84 & 5 & 3 & 0.69 \\
solutions, etc.? & 3.88 & 5 & 2.25 & 0.73 \\
\hline Does the spreadsheet exemplify the proper use of white apace? & & & \\
\hline Average
\end{tabular}

\section{Table 6 Analysis}

Table 6 possesses the highest agreements as well as some of the lowest agreements as to the importance of using consistent font features throughout the spreadsheet. These varied responses might be a result of not having any corporate-wide spreadsheet font feature-use policies and procedures, leading to a wide range of importance perceptions. Reviewing the respondents' written comments generally stated that following more stringent general design considerations depends upon whether the spreadsheet is used for solving a single problem or would be introduced as a production-use spreadsheet. Using visual markers (labels, comments, etc) becomes more important as the complexity of the spreadsheet purpose is developed. 
Table 7

Descriptive Statistics of Managers' and Partners' Perceptions Regarding The Introductory Section of the Survey

\begin{tabular}{|c|c|c|c|c|}
\hline Checklist Item & Mean & High & Low & St. Dev. \\
\hline Does the name of the spreadsheet appear in bold at the top? & 4.47 & 5 & 4 & 0.51 \\
\hline Does the heading properly identify the entity? & 4.37 & 5 & 3 & 0.60 \\
\hline Does the heading properly identify the name of the spreadsheet? & 4.53 & 5 & 4 & 0.51 \\
\hline Does the heading properly identify the date? & 4.58 & 5 & 3 & 0.61 \\
\hline Does the introductory spreadsheet information appear at the top? & 4.00 & 5 & 3 & 0.75 \\
\hline $\begin{array}{l}\text { For repeated-use spreadsheets, can introductory information be housed } \\
\text { in the header features? }\end{array}$ & 3.21 & 5 & 2 & 0.79 \\
\hline $\begin{array}{l}\text { Is the "assumption/input" area used to minimize the necessity of } \\
\text { changing spreadsheet items? }\end{array}$ & 3.68 & 5 & 3 & 0.89 \\
\hline Is the initial creation date identified? & 3.00 & 5 & 2 & 0.88 \\
\hline $\begin{array}{l}\text { If large and complex, is a "Table of Contents" identifying major } \\
\text { sections of the worksheet used? }\end{array}$ & 3.68 & 5 & 3 & 0.95 \\
\hline $\begin{array}{l}\text { Are "logical limit check" formulas useful to ensure reliable data for } \\
\text { input? }\end{array}$ & 3.79 & 5 & 3 & 0.54 \\
\hline If instructions are necessary, are they descriptive and complete? & 4.21 & 5 & 3 & 0.63 \\
\hline Average & 3.96 & 5 & 3 & 0.69 \\
\hline
\end{tabular}

\section{Table 7 Analysis}

Table 7 presents consensus among accounting managers and partners that header information identifying the name, entity, spreadsheet purpose, date and introductory materials be housed in the introductory section of a work file. Interestingly the initial creation date of the worksheet is not presumed critically important. Reviewing the respondents' written comments generally stated that the complexity of the spreadsheet should drive the complexity of the introduction section. Use of Table of Contents is useful and should be integrated to linking to separate worksheets within the workbook, breaking down the complexity of the spreadsheet purpose.

Table 8

Descriptive Statistics of Managers' and Partners' Perceptions Regarding The Main Body Section of the Survey

\begin{tabular}{|c|c|c|c|c|}
\hline Checklist Item & Mean & High & Low & St. Dev. \\
\hline Is logically-related spreadsheet information grouped together? & 4.58 & 5 & 4 & 0.51 \\
\hline $\begin{array}{l}\text { Are access titles, underlines, and column headings properly used and } \\
\text { justified? }\end{array}$ & 4.47 & 5 & 4 & 0.51 \\
\hline Are column widths appropriate? & 4.37 & 5 & 3 & 0.60 \\
\hline $\begin{array}{l}\text { Is the ordering of the spreadsheet information consistent with the } \\
\text { expected sequence? }\end{array}$ & 4.58 & 5 & 4 & 0.51 \\
\hline $\begin{array}{l}\text { Are label tabs for major spreadsheet/worksheet sections sufficiently } \\
\text { described? }\end{array}$ & 4.32 & 5 & 4 & 0.48 \\
\hline $\begin{array}{l}\text { Are calculation areas that do not need cell input segregated, } \\
\text { highlighted, and protected? }\end{array}$ & 4.21 & 5 & 3 & 0.79 \\
\hline $\begin{array}{l}\text { Are formatting schemes for numbers consistent throughout the } \\
\text { spreadsheet? }\end{array}$ & 4.68 & 5 & 4 & 0.50 \\
\hline Average & 4.45 & 5 & 3.71 & 0.56 \\
\hline
\end{tabular}

\section{Table 8 Analysis}

Table 8 has the highest collective recorded means, smallest collective range, and tightest collective standard deviations across all checklist items for the Main Body Section, which presents strong relative agreement of the importance of all these checklist items. Reviewing the respondents' written comments generally stated that consistent use of spreadsheet components is critical for readability and that labels used on workbook worksheets should not be too long or complex. 
Table 9

Descriptive Statistics of Managers' and Partners' Perceptions Regarding Conclusion Section

\begin{tabular}{|c|c|c|c|c|}
\hline Checklist Item & Mean & High & Low & St. Dev. \\
\hline Is the spreadsheet worksheet label designated in footer-center? & 2.89 & 5 & 1 & 0.88 \\
\hline Is the spreadsheet location and path label designated in footer-left? & 3.16 & 4 & 1 & 0.83 \\
\hline $\begin{array}{l}\text { Is the spreadsheet creator's initials or name, version update time, and } \\
\text { page number, in footer-right? }\end{array}$ & 3.05 & 4 & 1 & 0.85 \\
\hline $\begin{array}{l}\text { Does all concluding information appear at the bottom of the } \\
\text { spreadsheet or other logical area? }\end{array}$ & 3.95 & 5 & 2 & 0.91 \\
\hline Does the output appear reasonable? & 4.53 & 5 & 3 & 0.70 \\
\hline Average & 3.52 & 4.60 & 1.60 & 0.83 \\
\hline
\end{tabular}

\section{Table 9 Analysis}

Table 9 possesses the lowest agreement among CPAs as to the importance of these checklist items in the conclusion section of professional spreadsheet workpapers. The statistics illustrated the lowest mean agreement, widest collective range, and the widest standard deviation. The only element with general importance appears to be that the spreadsheet creator should assess whether the results of the spreadsheet appear reasonable. Reviewing the respondents' written comments stipulated that the conclusion components are necessary and the placement of spreadsheet results might better be located at the beginning of the spreadsheet. Care also must be taken in preparing the conclusion, with sensitivity as to who will read, use, or have access to the conclusions.

\section{CONCLUSION}

The lack of knowledge of the fundamentals of basic spreadsheet design and organization and the propensity to continue bad habits create the need for a spreadsheet design checklist. As several authors expressed in the literature review, organizations need to develop policies and procedures for spreadsheet organization and design. Training young professionals to be cognizant of firm-wide spreadsheet organization and design policies and procedures should be introduced to students. If good spreadsheet design habits are implemented in the academic accounting teaching environment, these spreadsheet design policies and procedures will, with higher probability, follow these students into their professional endeavors. Students and professionals should be encouraged to refer to the checklist often and integrate its recommendations consistently. The checklist that follows is the instrument used in the survey. Readers are encouraged to modify the existing checklist to represent the more highly agreed upon checklist items, as found in this study's pilot sample, or construct a checklist to suit their individual organization's needs. 


\section{Proper Spreadsheet Design Checklist}

\section{General Considerations:}

1. Take some time to determine how to properly design your spreadsheet

2. Break your spreadsheet down into logical modular components.

3. Make use of spreadsheet templates for repeated-use spreadsheets.

4. Always "save" your spreadsheet with the cursor in a blank cell near the top of each worksheet.

\section{General Design Questions:}

1. Are bold type, double-thick lines, varying colors, and shaded areas used appropriately and consistently?

2. Is the font style and font size appropriate for the spreadsheet?

3. Are varying font sizes consistent as to size and use - text, access titles, solutions, etc?

4. Does the spreadsheet exemplify the proper use of "white space"?

\begin{tabular}{|l|l|l|}
\multicolumn{1}{c}{ Yes } & \multicolumn{1}{c}{ No } & \multicolumn{1}{c|}{ N/A } \\
\hline & & \\
\hline & & \\
\hline & & \\
\hline & & \\
\hline
\end{tabular}

\section{Introductory Section:}

1. Does the name of the spreadsheet appear in bold and at the top?

2. Does the heading properly identify the following components?

a. Name of the entity?

b. Name of the spreadsheet?

c. Date?

3. Does all the introductory spreadsheet information appear at the top of the form?

4. For repeated-use spreadsheets, can introductory information be housed in the header feature?

5. Is an "Assumptions/Input" area used to minimize the necessity of changing spreadsheet items?

6. Is initial creation date identified?

7. If spreadsheet is large and complex is a "Table of Contents" identifying major section worksheet and/or cell locations?

8. Are "logical limit-check" formulas useful to insure reliable data for input?

9. If instructions are necessary, are they descriptive and complete?

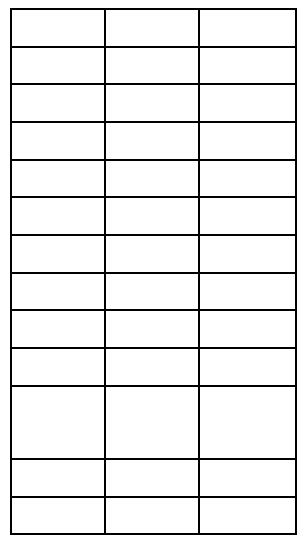

Main Body:

1. Is logically-related spreadsheet information grouped together?

2. Are access titles, underlines, column headings properly used and justified?

3. Are column widths appropriate?

4. Is the ordering of the spreadsheet information (e.g. data items) consistent with the expected sequence?

5. Are labels/tabs for major spreadsheet/worksheet sections sufficiently described?

6. Are calculation areas that do not need cell input segregated, highlighted, and protected?

7. Are formatting schemes for numbers consistent throughout the spreadsheet?

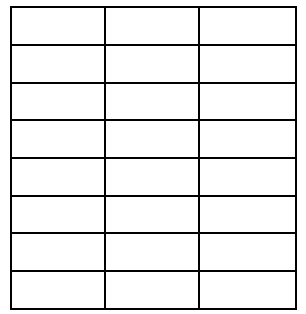

\section{Conclusion:}

1. Is the spreadsheet worksheet label designated in footer-center?

2. Is the spreadsheet location and pathway label designated in footer-left?

3. Is the spreadsheet creator's initials (name), version update date, and page number in footer-right?

4. Do all concluding information appear at the bottom of the spreadsheet or other logical area?

5. Does the output appear reasonable?

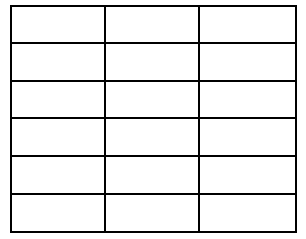

\section{AUTHOR INFORMATION}

Jeffrey N. Barnes is an Associate Professor of Accounting at Southern Utah University. He is a CPA and earned his Master of Accountancy from Brigham Young University in 1984. He is currently earning his doctorate degree from the University of Phoenix's School of Advanced Studies. He worked several years with PricewaterhouseCoopers, before entering academe. He teaches accounting information systems and auditing courses. He has been with Southern Utah University since August 1986.

David Tufte is an Associate Professor of Economics at Southern Utah University. He earned a Ph.D. in Economics from the University at Buffalo, SUNY in 1992. He was a faculty member at the University of New Orleans from 1992-2000; he earned tenure in 1998, and was then appointed director of the Ph.D. program in Financial Economics. 
He has held visiting positions at Tulane University, the University of Alabama, the University of Utah, and the University of New Orleans. He has been with Southern Utah University since 2001.

David S. Christensen is a Professor of Accounting at the Southern Utah University. He earned a Ph.D. in Accounting from the University of Nebraska at Lincoln in 1987. In 1994, he retired from a career with the United States Air Force. He has taught accounting and cost management courses at the Air Force Institute of Technology from 1987 to 1997, and at the University of West Florida from 1997-1998. He has been at Southern Utah University since August 1998.

\section{REFERENCES}

1. AICPA. Journal of Accountancy. Most recent years' monthly publications have either a "Technology Workshop" section or other spreadsheet-related journal department.

2. Albrecht, W., \& Sack, R. (2000). Accounting education: Charting the course through a perilous future. Accounting Education Series 16. Sarasota, FL: American Accounting Association.

3. Alexander, A. (2006). Living with =sum. Accounting Today, 20(17), 22-25.

4. Bhavnani, S. K., Peck, F. A. \& Reif, F. (2008) Strategy-based instruction: Lessons Learned in Teaching the Effective and Efficient Use of Computer Applications. ACM Transactions on Computer-Human Interaction. 15(1), 2-43.

5. $\quad$ Bender, E. (July, 2004). Godfather of the spreadsheet. PCWorld, 22(7), 38.

6. Berglas, A., \& Hoare, P. (July/August, 1999). Spreadsheet errors, risks, and techniques. Management Accounting, 46-47.

7. Bissell, J. L., \& Needle, S. (May, 1986). Spreadsheet planning and design, Journal of Accountancy, 161(5), 110-128.

8. Broomley, R. G. (December 1985). Template design and review: How to prevent spreadsheet disasters. Journal of Accountancy, 160(6), 124-145.

9. Brown, P. S., \& Gould, J. D. (July, 1987). An experimental study of people creating spreadsheets. ACM Transactions on Office Information Systems, 5(3), 258-272.

10. Chadwick, D., Knight, J. \& Clipsham, P. (1997). Information integrity in end-user systems, in Integrity and Internal Control in Information Systems, Vol. 1: Increasing the Confidence in Information Systems, S. Jajodia, W. list, G. McGregor, and L. Strous, Eds., Chapmen \& Hall: London, pp. 273-292. Retrieved August 20, 2009, from http://panko.shidler.hawaii.edu/SSR/index.htm

11. Christensen, D. S., \& Rees, D. (2002). An analysis of the business communication skills needed by entrylevel accountants. Mountain Plains Journal of Business and Economics, 3, General Research, pp. 1-13.

12. Coffee, P. (March 22, 2004). 25 years in a cell. eWeek, 21(12), 70.

13. Cragg, P. G., \& King, M. (August, 1993). Spreadsheet modeling abuse: An opportunity for OR? Journal of the Operational Research Society 44(8), 743-752.

14. Durfee, D. (Summer, 2004). Spreadsheet hell? CFO-IT, 30-35.

15. Floyd, B. D., \& Pyun, J. (October, 1987). Errors in spreadsheet use. Working Paper 167. Center for Research on Information Systems. Information Systems Department. New York University. New York.

16. Gaide, S. (November 15, 2004). Are technical skills core competencies? How do we measure up? Distance Education Report, 8(22), 5-7.

17. Hassinen, K. (1988). An experimental study of spreadsheet errors made by novice spreadsheet users. Department of Computer Science. University of Joensuu. P. O. Box 111, SF-80101 Joensuu, Finland.

18. Janvrin, D., \& Morrison, J. (2000a). Factors influencing risks and outcomes in end-user development. Proceedings of the Twenty-Ninth Hawaii International Conference on System Sciences. Kihei, Maui, Hawaii.

19. Janvrin, D., \& Morrison, J. (2000b). Using a structured design approach to reduce risks in end user spreadsheet development. Information \& Management, 37(1), 1-12.

20. Keefe, L. (January 2000). Get it together with spreadsheets. Fleet Equipment, 26(1), 4.

21. Kreie, J., \& Pendley, J. (November, 1998). Spreadsheet safety: Designing the perfect file. Journal of Accountancy, 186(5), 31-51.

22. Kreie, J., Cronan, T. P., Pendley, J., \& Renwick, J. S. (2000). Application development by end-users: Can quality be improved? Decision Support Systems, 29(1), 143-152. 
23. Lehman, Mark W. (January, 2001). Make your mark in spreadsheets: Document files with comments and tick marks. Journal of Accountancy, 191(1), 29-36.

24. Lerch, F. J. (1988). Computerized financial planning: Discovering cognitive difficulties in knowledge building. Unpublished doctoral dissertation. University of Michigan. Ann Arbor, Michigan.

25. Mahoney, L. S., \& Welch, J. K. (February, 2003). Spreadsheets with something extra. Journal of Accountancy, 195(2), 52-56.

26. Olson, J. R., \& Nilsen, E. (1987-1988). Analysis of the cognition involved in spreadsheet interaction. Human-Computer Interaction, 3(4), 309-349.

27. Panko, R. R., \& Halverson, R. P., Jr. (August, 1998). An experiment in collaborative spreadsheet development. Working Paper, College of Business Administration, University of Hawaii, 2404 Maile Way, Honolulu, HI 96822.

28. Panko, R. R., \& Halverson, R. P, Jr. (Spring, 1997). Are two heads better than one? (At reducing spreadsheet errors in spreadsheet modeling). Office Systems Research Journal, 15(1), 21-32.

29. Panko, R. R., \& Sprague, R. H., Jr. (April, 1999). Hitting the wall: Errors in developing and code inspecting a 'simple' spreadsheet models. Decision Support Systems, 22(4), 337-353.

30. Panko, R. R. (2008, revised). What we know about spreadsheet errors. Journal of End User Computing's Special issue on scaling up end user development, 10(2), 15-21 (originally published Spring, 1998)

31. Panko, R. (2009). Spreadsheet Research Website. Retrieved August 20, 2009 from http://panko.shidler.hawaii.edu/SSR/index.htm

32. Panko, R. R., \& Sprague, R. H., Jr. (1999). Experiments in spreadsheet development: Task difficulty, level of expertise, and error rate. Working Paper. College of Business Administration, University of Hawaii, 2404 Maile Way, Honolulu, HI 96822.

33. Pemberton, J. D., \& Robson, A. J. (2000). Spreadsheets in business. Industrial Management \& Data Systems, 100(8), 379-388.

34. Porter, A. (2005). Personal discussion with an Associate Professor of Management, who used the Spreadsheet Design Checklist during the 2004-2005. Southern Utah University, Cedar City, Utah.

35. Powell, S. G., \& Baker, K. R. (2004). The art of modeling with spreadsheets: Management science, spreadsheet engineering, and modeling craft. Hoboken, New Jersey: John Wiley \& Sons.

36. Ragsdale, C. (2004). 7 goals and guidelines for spreadsheet design. Spreadsheet Modeling \& Decision Analysis. $4^{\text {th }}$ ed. Mason, Ohio: Thompson-Southwestern, 62-63.

37. Reimann, P., \& Neubert C. (2000). The role of self-explanation in learning to use a spreadsheet through examples. Journal of Computer Assisted Learning, 16(4), 316-325.

38. Romney, M. B., \& Steinbart, P. J. (2003). Accounting Information Systems, $9^{\text {th }}$ ed. Upper Saddle River, New Jersey, Prentice-Hall.

39. Wampler, Bruce. (May 2000). A Spreadsheet Template for Installment Loan Amortization Tables. The CPA Journal, 70(5), 82-84.

40. Whittaker, D. (1999). Spreadsheet errors and techniques for finding them. Management Accounting, 50-51.

\section{Endnotes}

${ }_{1}^{1}$ Quite literally, Olson and Nilsen (1987-8), Lerch (1988), and Floyd and Pyun (1997) showed that data input errors are common.

2 The websites of Panko and Raffensberger offer comprehensive listings of references in this area by topic. 